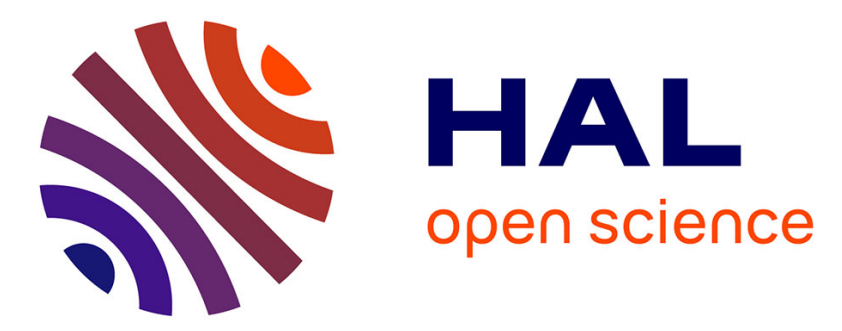

\title{
Organic semiconductor colloids: From the knowledge acquired in photovoltaics to the generation of solar hydrogen fuel
}

Natalie Holmes, Sylvain Chambon, Alexandre Holmes, Xiaoxue Xu, Kazuhiko Hirakawa, Elise Deniau-Lejeune, Christine Lartigau-Dagron, Antoine

Bousquet

\section{To cite this version:}

Natalie Holmes, Sylvain Chambon, Alexandre Holmes, Xiaoxue Xu, Kazuhiko Hirakawa, et al.. Organic semiconductor colloids: From the knowledge acquired in photovoltaics to the generation of solar hydrogen fuel. Current Opinion in Colloid \& Interface Science, 2021, 56, pp.101511. 10.1016/j.cocis.2021.101511 . hal-03418784

\section{HAL Id: hal-03418784 \\ https://hal-univ-pau.archives-ouvertes.fr/hal-03418784}

Submitted on 9 Nov 2021

HAL is a multi-disciplinary open access archive for the deposit and dissemination of scientific research documents, whether they are published or not. The documents may come from teaching and research institutions in France or abroad, or from public or private research centers.
L'archive ouverte pluridisciplinaire HAL, est destinée au dépôt et à la diffusion de documents scientifiques de niveau recherche, publiés ou non, émanant des établissements d'enseignement et de recherche français ou étrangers, des laboratoires publics ou privés. 


\title{
Organic Semiconductor Colloids: From the Knowledge Acquired in Photovoltaics to the Generation of Solar Hydrogen Fuel
}

Natalie P. Holmes, ${ }^{*}$ Sylvain Chambon, ${ }^{2 *}$ Alexandre Holmes, ${ }^{3}$ Xiaoxue $\mathrm{Xu},{ }^{4}$ Kazuhiko Hirakawa, ${ }^{2}$ Elise Deniau, ${ }^{3}$ Christine Lartigau-Dagron, ${ }^{3}$ Antoine Bousquet ${ }^{3 *}$

${ }^{1}$ Australian Centre for Microscopy and Microanalysis, The University of Sydney, Madsen Building F09, NSW 2006, Australia

${ }^{2}$ LIMMS/CNRS-IIS (IRL2820), Institute of Industrial Science, The University of Tokyo, 4-6-1 Komaba, Meguro-ku, Tokyo, 153-8505, Japan

${ }^{3}$ Universite de Pau et des Pays de l'Adour, E2S UPPA, CNRS, IPREM, Pau, France

${ }^{4}$ Institute for Biomedical Materials and Devices (IBMD)/Faculty of Science, University of Technology Sydney, NSW 2007, Australia

*Corresponding Authors: natalie.holmes@sydney.edu.au; chambon@iis.u-tokyo.ac.jp; antoine.bousquet@univ-pau.fr

This review comes from a themed issue on Colloid Science for a Sustainable Future.

\section{Keywords}

nanoparticle, solar fuel, photocatalysis, hydrogen evolution, morphology, semiconductor, conjugated polymer

\begin{abstract}
The recent interest in the application of organic semiconductor colloids to photocatalytic hydrogen evolution has sparked the need for an assessment of the current state of this research field. Here we showcase how the lessons learnt from organic photovoltaics (OPV) research can be applied to new applications in the generation of solar fuels, such as in photocatalytic hydrogen evolution. Photovoltaics generated from organic semiconductor nanoparticles started out with a power conversion efficiency (PCE) at less than $0.01 \%$ in 2003, since then the technology witnessed a steady climb to $7.5 \%$ reported in 2018. A large fraction of this technology improvement can be attributed to morphology improvement of the organic semiconductor colloids, improvements which can now be transferred to benefit the field of photocatalytic hydrogen evolution. We begin with an introduction to conjugated materials, then move to a thorough description of nanoparticle dispersion processes, comprising the miniemulsion and the nanoprecipitation methods, before moving to a summary of the different morphologies encountered in organic nanoparticles, their impact on OPV performance and how
\end{abstract}


this parameter is of crucial importance for photocatalytic hydrogen generation. Indeed, organic semiconductor colloids conveniently provide the field of photocatalytic hydrogen generation with a nanoengineering toolkit upon which to customize morphologies in order to increase photocatalytic activity and enhance hydrogen evolution rates (HER).

\section{Introduction}

As a vast source of energy, the sun's photons are one of the best candidates to solve the energy and environmental crisis the world is facing. The main drawback of photovoltaics is that the electricity produced should be consumed instantaneously otherwise it is lost. Batteries and solar fuels, which transform solar irradiation into chemical bonds have been developed as energy storage systems. Batteries are challenged by the frequent use of lithium and most of the fuels are producing $\mathrm{CO}_{2}$ as a side product, which obviously will not answer the global warming problem. However, hydrogen $\left(\mathrm{H}_{2}\right)$ is a clean fuel because it only produces electricity and $\mathrm{H}_{2} \mathrm{O}$. Nowadays, the vast majority ( $>95 \%$ ) of global hydrogen is produced from fossil steam methane reforming, a process emitting $\mathrm{CO}_{2}$. Recently, $\mathrm{H}_{2}$ production via photocatalytic water splitting has emerged as a fantastic solution to store solar energy in a dispensable fuel that does not produce $\mathrm{CO}_{2}$, neither at the fabrication nor consumption stages. In this context, Pinaud et al. have modeled and calculated by life cycle analysis that a colloidal system, in which the photocatalysts are in the form of nanoparticles dispersed in water, would be the cheapest way to produce $\mathrm{H}_{2}$, mainly because of increased interface area compared to a film but also due to lower initial capital cost. ${ }^{1}$ In 1985, Yanagida et al. paved the way for the use of organic semiconductors to perform photocatalytic hydrogen evolution, by demonstrating the performance of conjugated poly( $p$-phenylene) as a photocatalyst. $^{2}$ In this review we will demonstrate how the more recent knowledge acquired from the field of organic photovoltaics, in particular in organic semiconductor nanoparticle synthesis, has advanced the development of efficient systems to produce $\mathrm{H}_{2}$.

The development of organic nanoparticles as preparations of colloidal inks has received significant consideration for various applications in the past three decades. Recently, nanoparticles were developed from semiconducting conjugated polymers for the photovoltaics application, opening the field of environmentally-friendly processes as alternatives to classical options which are typically in toxic organic solvents. Although this field is very young, many lessons and insights were extracted from the global research effort. Recently, Holmes et al. published a review on this specific subject, and we invite the reader to access this article for a 
deeper understanding of the impact of nanoparticle synthesis on organic photovoltaic device performance. $^{3}$

Nanoparticles of organic semiconductors are produced via a self-assembly process, rather than a growth process (polymerization), hence we begin this review by briefly comparing the two main routes of nanoparticle preparation to provide context for a broader audience in the colloid science space. Functional nanoparticles are synthesized via two main routes, growth or selfassembly, the choice of route being dependent on the nature of the starting materials and the final application of the nanomaterials.

Growth: The formation process of nanoparticles (either inorganic or organic) from a solution of ions (for inorganic nanoparticles) or small molecules (for organic nanoparticles) is predominantly via nucleation and growth. ${ }^{4,5}$ Nucleation is the process whereby droplets/nuclei (seeds) act as templates for polymerization (for organic nanoparticles) or crystal growth (for inorganic nanoparticles). Homogeneous nucleation, a typical classical nucleation process, occurs when nuclei form uniformly throughout the parent (or continuous) phase. ${ }^{6}$

Self-Assembly: By comparison, the formation of nanoparticles via self-assembly of macromolecules is a post-polymerization route for forming organic nanoparticles. The driving force for the self-assembly formation is usually a surface energy minimization process, where each material type moves to its final location in order for the system to reach equilibrium. For example, the self-assembly of nanoparticles from diblock copolymers, where block $\mathrm{A}$ is insoluble (or hydrophobic in a hydrophilic parent phase) compared to block B and hence selfassembly into a core-shell structure with a block A core and block B shell occurs. ${ }^{7}$ When beginning instead with two immiscible liquid phases and employing a surfactant, a nanoparticle dispersion can be generated first by forming a liquid-liquid colloidal dispersion (an emulsion), and then a solid-liquid colloidal dispersion by removing the solvent of the dispersed phase droplets via evaporation, hence converting the polymer material originally dissolved in that phase to solid nanospheres.

The development of organic semiconductor nanoparticles was mainly motivated by the search for avenues to reduce the environmental impact of OPV technology and the replacement of halogeno-aromatic solvents. As a consequence, developing water or alcohol based colloidal inks would afford environmentally-friendly processability of photovoltaic modules. The nanoscale morphology of the organic active layer is of utmost importance in the OPV field. Indeed, in order to reach optimum photovoltaic performance, a large part of the research in the 
OPV field is dedicated to optimization of the bulk heterojunction (BHJ) morphology to reach, on the one hand, nanoscale domain size that more closely matches exciton diffusion length (approx. $10 \mathrm{~nm}$ ) and, on the other hand, conduction pathways for both charges. Due to this specific target for domain size, much research effort has been invested into producing organic semiconductor nanoparticles with controlled morphologies and sizes, including core-shell, molecularly intermixed, distributed nano-domains and biphasic/Janus. This detailed morphology investigation and optimization can now benefit the field of photocatalytic hydrogen evolution in which a strong drawback of organic materials is the loss of excitons before reaching the interface with water, the solvent of the $\mathrm{H}^{+}$reagent. This is only one example of the formidable lessons extracted from photovoltaics and others will be reported herein.

The plan of this review is to start with (macro)molecules, the building blocks, move to nanoparticle synthesis, and end with hydrogen photocatalysis applications. We describe the basics of conjugated materials which constitute the organic semiconductors used as building blocks for the organic nanoparticles. Then we detail the organic nanoparticle preparation via colloidal dispersion processes, both the miniemulsion and the nanoprecipitation methods being covered, and the key parameters controlling the morphology and how it has impacted OPV performance. Finally, we detail the new application area of photocatalytic hydrogen evolution and showcase how the knowledge of nanoparticle material development for photovoltaics can be applied to this alternate field.

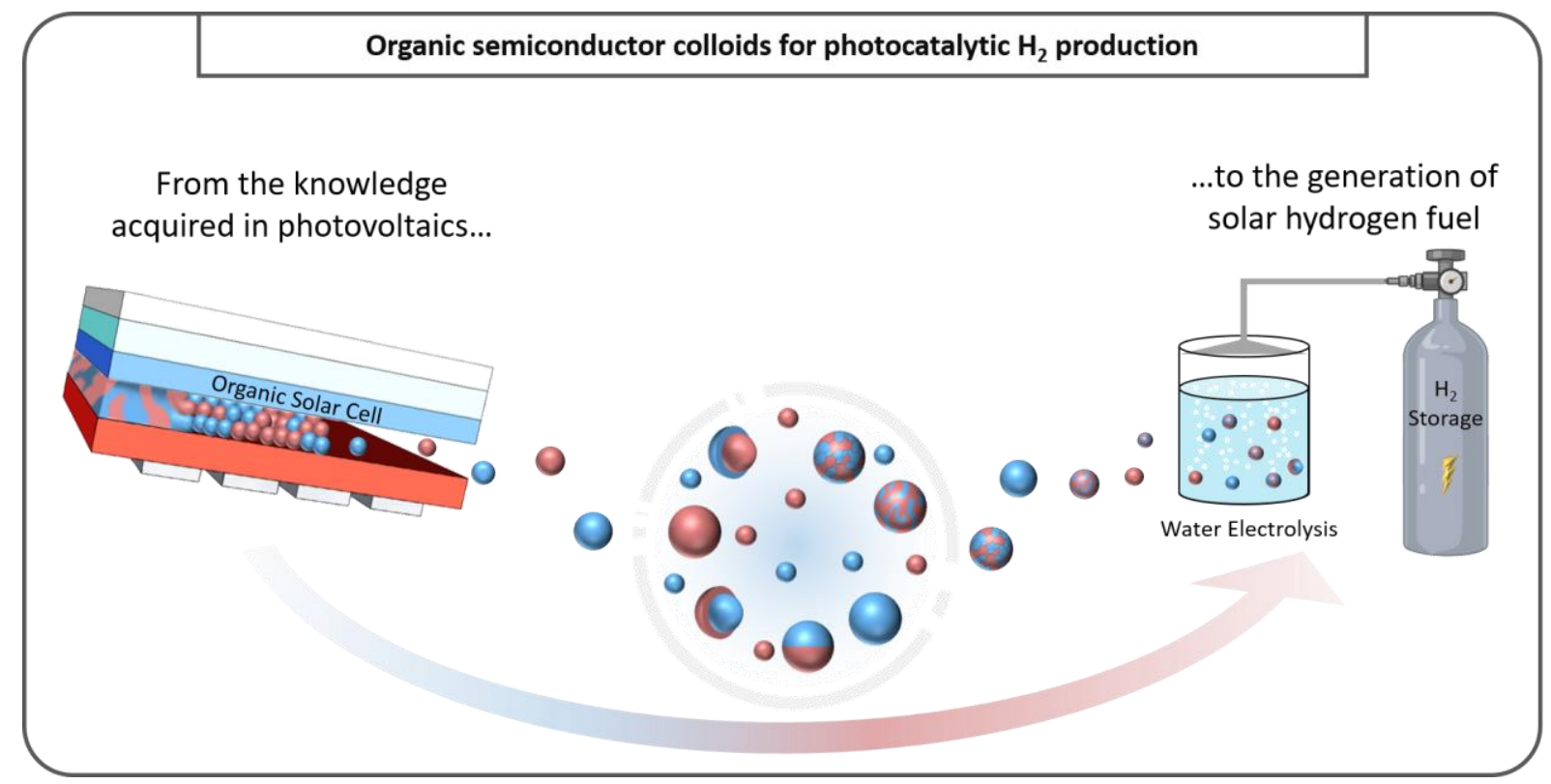

Figure 1. Graphical overview of the focus of this review. Applying organic semiconductor colloids in photocatalytic hydrogen generation using the knowledge acquired from photovoltaics research. 


\section{Conjugated Materials}

The unexpected observation of a conducting polyacetylene thin film, thanks to the undeliberate addition of a catalyst amount 1000 times higher than the traditional amount by a student of Hideki Shirakawa, ushered in the use of conjugated polymers in electronics. ${ }^{8}$ This discovery was awarded to him and his collaborators Alan Heeger and Alan MacDiarmid with the Nobel Prize in chemistry in 2000. From this starting point in the field of synthetic metals, several discoveries of conjugated polymers in the early 1990s, such as the electroluminescence of poly ( $p$-phenylene vinylene) (PPV) or the ultra-fast charge transfer from PPV to fullerene, took place.

The semiconducting behavior in organic materials originates from the alternation of single $(\sigma)$ and double $(\pi)$ carbon bonds, termed $\pi$-conjugation. Each $s p^{2}$ carbon presents three $s p^{2}$ hybridized orbitals providing covalent $\sigma$-bonds with neighboring carbons, plus the remaining unhybridized $2 p_{z}$ orbital. Therefore, the overlap of these $p_{z}$ orbitals forms a delocalized out-ofplane $\pi$-electron cloud along the conjugated backbone (Figure 2a). This leads to the electron motion owing to the optoelectronic and charge transport properties in these materials.

In comparison with inorganic semiconductors, the valence band corresponds to the highest occupied molecular orbital (HOMO), and the conduction band to the lowest unoccupied molecular orbital (LUMO). The HOMO-LUMO energy difference is called the energy band gap. As shown in Figure 2b, this difference decreases as the number of conjugated bonds in the backbone increases. The energy corresponding to the first optical transition explains the bathochromic absorption. In an infinite chain, the molecular orbitals are so close to each other that they become indiscernible and constitute the valence and conduction bands. In the band model, the electronic structure affords the electrical properties of the material, among metals, semiconductors and insulators. Semiconductors are characterized by an energy band gap below $3 \mathrm{eV}$. 


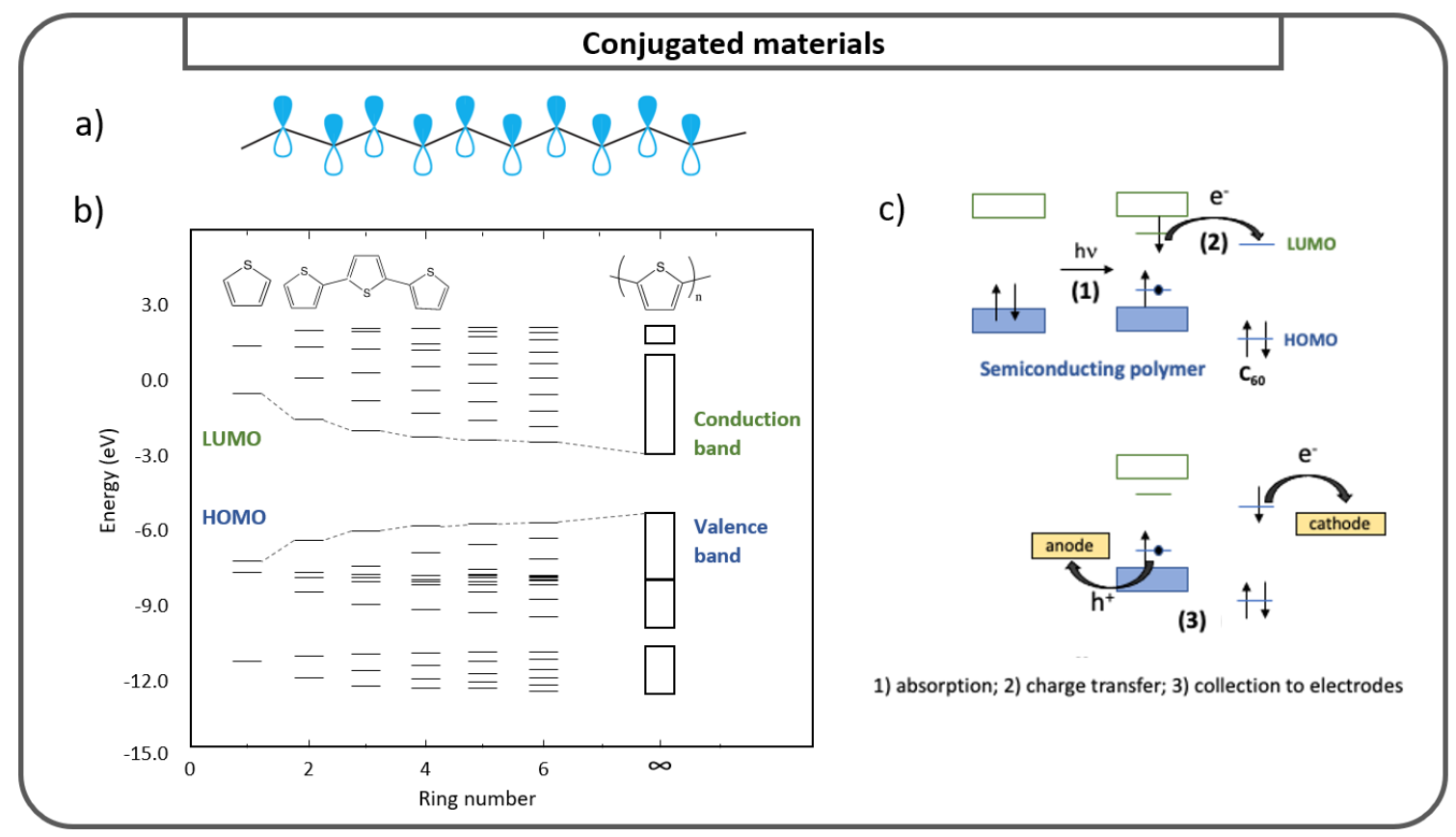

Figure 2. (a) Illustration of $s p^{2}$ hybridization along a $\pi$-conjugated polymer chain; (b) calculated band structure of polythiophene (adapted from Salzner et al..$^{9}$ ); (c) processes occurring during photoconversion in an organic solar cell, in particular the ultra-fast charge transfer.

Semiconducting conjugated polymers (donor) are good candidates to be used in an active layer, mixed with an electron acceptor material, either fullerene, small molecule or polymer in organic photovoltaic devices. The photoconversion then consists of photon absorption by either the donor or the acceptor material, generating a highly bound electron-hole pair (exciton) that can only be separated by an internal field created by proximity of the donor and acceptor materials (Figure 2c). Nevertheless, the properties of organic semiconductor materials make them suitable for different types of electronic devices: organic light-emitting diodes, organic thin film transistors, sensors or even for hydrogen production, which is the scope of this review.

\section{Dispersion Processes}

Nanoparticles (NPs) of conjugated materials are prepared mainly by post-polymerization techniques such as miniemulsion and nanoprecipitation. In the miniemulsion process, organic semiconductor nanoparticles are formed from an emulsified droplet solution, and usually require a water-immiscible solvent. By contrast, in nanoprecipitation the semiconductors are precipitated by rapidly mixing the material solution with the anti-solvent, and require two miscible solvents. In both cases, the organic solvent is finally removed under high temperature. Interestingly, experimental parameters used in the preparation show a significant influence on the size of nanoparticles. In the following section we describe both techniques by emphasizing their advantages and limitations in the dispersion of conjugated polymer nanoparticles. 
Miniemulsion is the most common method used for the preparation of conjugated nanoparticles. The conjugated material is first dissolved in a good solvent (most of the time chloroform), and an aqueous phase containing surfactant molecules is then added to the organic solution. Nanodroplets of organic phase are produced by applying high shear using ultrasonic waves or high-speed homogenization. Evaporation of the organic solvent from the dispersed phase leads to the formation of solid nanoparticles dispersed in water. An additional step aiming to remove the excess of free-surfactant and also to reduce the volume of the aqueous phase, in order to concentrate the dispersion, is often required (Figure 3).

The first report of the preparation of nanoparticles of organic semiconductors via a miniemulsion process was in 2002 by Landfester et al. ${ }^{10}$ The authors prepared nanoparticles of three different conjugated polymers (methyl substituted ladder-type poly( $p$-phenylene) (MeLPPP), polyfluorene (PF) and polycyclopenta-dithiophene. They used sodium dodecyl sulfate (SDS) as surfactant to stabilize the droplets from collision and aggregation and the polymer solution was sufficiently hydrophobic to prevent Ostwald ripening. Stable dispersions were obtained with nanoparticle sizes ranging from 75 to $250 \mathrm{~nm}$, by varying the amount of SDS, yielding a solids content of 2.2 to $9.3 \mathrm{wt} \%$ after evaporation of the organic solvent (chloroform in this case).

Varying the experimental parameters of the miniemulsion preparation can easily control the nanoparticle size. Indeed, the size of the nanoparticles is strongly influenced by the initial concentration of the conjugated polymer in the organic phase: the higher the concentration, the larger the diameter. For example, Xie et al. reported the increase of the active material (poly(diketopyrrolopyrrole-quinquethiophene)) low band gap alternating copolymer (PDPP5T) and phenyl- $\mathrm{C}_{71}$-butyric acid methyl ester $\left(\mathrm{PC}_{71} \mathrm{BM}\right)$ concentration from 15 to 40 mg.mL ${ }^{-1}$ leading to an increase in the nanoparticle size from 5 to $107 \mathrm{~nm}$. ${ }^{11}$ The trend can be explained by the presence of more active material in the polymer solution droplets during the miniemulsion generation, resulting in an increase in the nanoparticle size after organic solvent evaporation. Depending on the semiconductor used, it is however important to adjust the organic phase concentration as a function of its solubility in the primary organic solvent, in order to avoid aggregation.

The shear force applied during the miniemulsion process, by using sonifiers or high-pressure homogenizers, is also a highly important parameter. Increasing the sonication power and/or the sonication time enables the formation of smaller nanoparticles. 
The presence of surfactant enhances the colloidal stability of the dispersion but can also affect the particle size. Increasing the amount of surfactant leads to smaller and more numerous nanodroplets leading to smaller nanoparticles. For certain applications in organic electronics, the presence of surfactant is a limitation due to its insulating character. However, thanks to the presence of these molecules, the miniemulsion method enables the preparation of highly stable dispersions exhibiting high solids content.

Nanoprecipitation is an alternative to the miniemulsion technique, enabling the generation of surfactant-free nanoparticle dispersions. It requires the selection of a solvent and a non-solvent of the conjugated materials that are fully miscible. The process is simple: the semiconductor is first dissolved in an organic solvent and then mixed into a large volume of anti-solvent under stirring. In general, the solvent/anti-solvent couple is THF/water however chloroform/alcohol systems have also been reported. The solution becomes an anti-solvent for the conjugated material and leads to its precipitation into small particles in a continuous phase of both solvent and anti-solvent (Figure 3).

The addition rate is quite important in order to obtain stable dispersions exhibiting narrow size distributions. Although the literature mostly reports a slow addition of the organic phase into the anti-solvent under stirring, it has been shown that a quick addition of a large volume of anti-solvent into the organic phase leads to more homogeneous dispersion with a narrow size distribution of nanoparticles (Ouzo effect). ${ }^{12}$ In addition, the use of suitable mixing techniques, which increases the homogenization rate (high-shear and ultra-sonification process), leads to smaller nanoparticles and narrow size distributions.

The main advantage of using nanoprecipitation is that the preparation does not involve the use of surfactants. Moreover, using this method, it is also possible to tune the size of nanoparticles by adjusting the polymer concentration. The final size reached by the nanoparticles varies as a power law of the polymer concentration in the solvent. Additionally, the polymer molar mass influences the nanoparticle size, with larger nanoparticles obtained for higher polymer molar mass.

The main drawback of the nanoprecipitation process is the low colloidal stability for high solids content, limiting the final dispersion to low solids content. The addition of a surfactant in the nanoprecipitation process is a way to enhance the stability of the dispersion, and produce more concentrated dispersions. Xie et al. reached a final nanoparticle concentration of $2.5 \mathrm{mg} . \mathrm{mL}^{-1}$ prior to concentration, using Pluronic F127, a poloxamer and non-ionic surfactant. This 
surfactant has the advantage of possessing a temperature-sensitive critical micelle concentration (TS-CMC) enabling the removal of the surfactant excess by centrifugal dialysis at low temperature. ${ }^{13}$ The authors showed that efficient and environmentally-friendly solar cells could be processed by using an aqueous dispersion, holding the current record in PCE for OPV devices made from nanoparticles at $7.5 \%$ for the PBQ-QF:ITIC system. This value directly compared to a PCE of $4.4 \%$ when using SDS as surfactant and the miniemulsion technique.

Amphiphilic copolymers can also be used as surfactant. Several studies reported the use of a polystyrene-comb-poly(ethylene oxide) copolymer as surfactant and showed that stabilizing the conjugated NPs with this surfactant greatly improved the photocatalytic performance of hydrogen evolution compared to the pristine nanoparticles. ${ }^{14-16}$

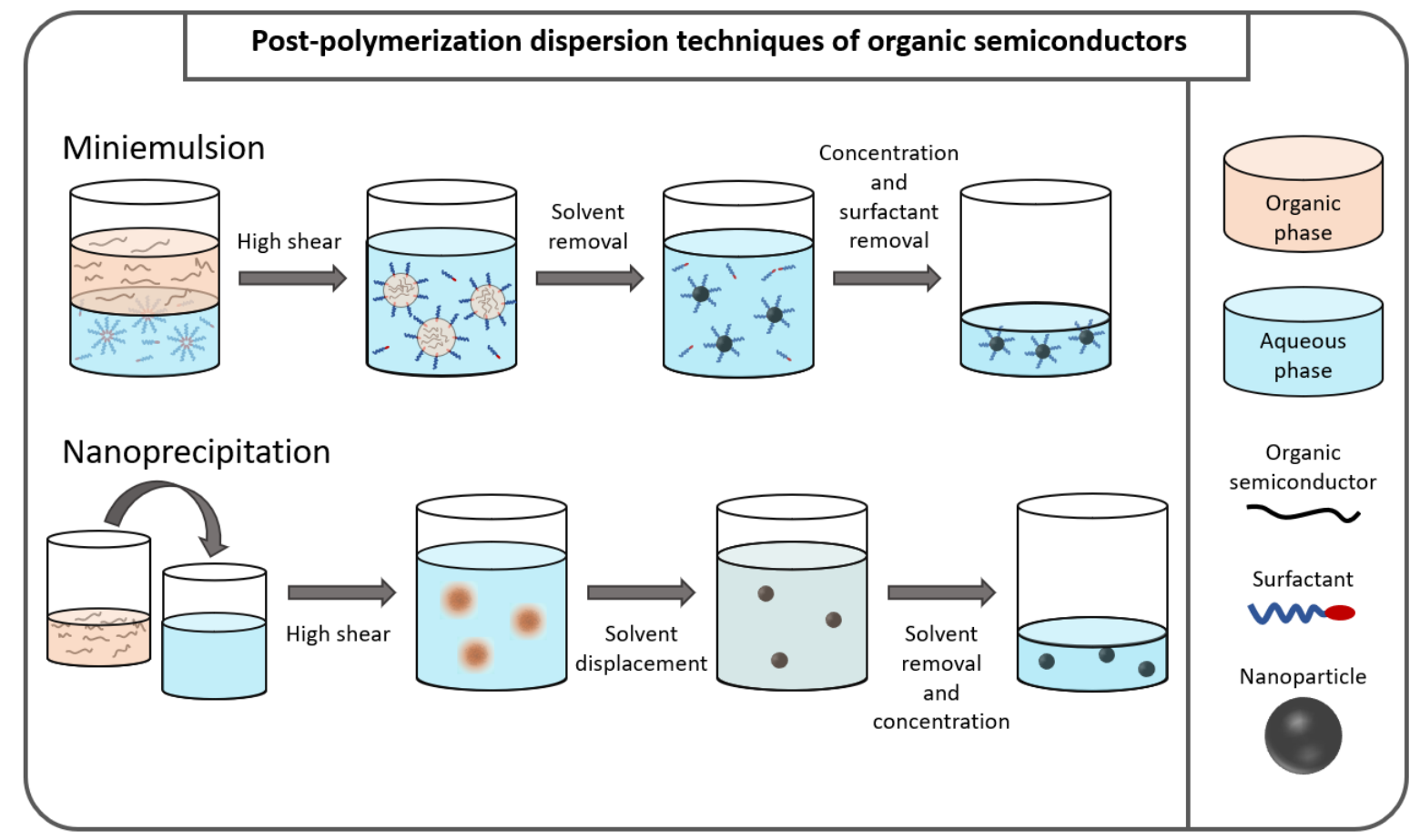

Figure 3. Preparation of conjugated polymer nanoparticles by miniemulsion or nanoprecipitation technique.

\section{From Photovoltaics Knowledge...}

Organic semiconductor nanoparticles were first used in the field of organic photovoltaics with the work of Landfester et al. in 2002. ${ }^{10}$ In their first article utilizing organic semiconductor nanoparticles to fabricate OPV devices, they selected two conjugated polymers, PFB (poly $(9,9-$ dioctylfluorene-co-N,N-bis(4-butylphenyl)-N,N- diphenyl-1,4-phenylenediamine) as electron donor material and F8BT (poly(9,9-dioctylfluorene-co-benzothiadiazole) as electron acceptor 
material and prepared composite nanoparticles using the miniemulsion technique. Although device efficiency was very low (1.7\% maximum external quantum efficiency), a photovoltaic effect had been achieved as a proof of concept for the use of organic nanoparticles in electronic devices. ${ }^{17}$

For the entire journey in the development of organic electronic devices based on colloidal dispersions, probing the precise nanostructure of the colloidal nanoparticles of donor and acceptor materials has been of great interest to researchers due to the substantial influence nanostructure has on device performance. While the available morphology categories of nanoparticles range from phase-separated core-shell, biphasic and eccentric to molecularly intermixed, for two component systems, the most reported morphology type for donor-acceptor nanoparticles has been limited to two categories: core-shell and molecularly intermixed.

Figure 4 presents a library of organic semiconductor nanoparticle morphology types and examples of such morphologies being reported in the literature, in order to provide a comprehensive overview of categorization of morphologies. The internal morphology of organic semiconductor nanoparticles forms via self-assembly, particularly in the case of miniemulsion-prepared nanoparticles of donor and acceptor.

A core-shell morphology (Figure 4a,b) is most commonly reported when the miniemulsion method is applied to nanoparticle preparation. Here the donor and acceptor materials selfarrange in the miniemulsion droplets to minimize surface energy while the oil-phase solvent (e.g. chloroform or o-xylene ${ }^{18}$ ) is being removed via thermal evaporation. When a polymer donor is combined with a fullerene acceptor, the fullerene acceptor invariably has a higher surface energy, $38.2 \mathrm{~mJ} \mathrm{~m}^{-2}$ for $\mathrm{PC}_{61} \mathrm{BM}$ and $39 \mathrm{~mJ} \mathrm{~m}^{-2}$ for $\mathrm{PC}_{71} \mathrm{BM}$, and moves to the core of the nanoparticle, while the polymer moves to occupy the shell (Figure 4a). Hence a donor-rich shell and acceptor-rich core is formed, which was reported for TQ1:PC ${ }_{71} \mathrm{BM}^{19}$ and $\mathrm{P} 3 \mathrm{HT}: \mathrm{PC}_{61} \mathrm{BM}^{20}$ nanoparticles. In the OPV field, fullerene derivatives $\left(\mathrm{PC}_{61} \mathrm{BM}, \mathrm{PC}_{71} \mathrm{BM}\right.$, ICBA) have been for a long time the standard organic semiconductor used as acceptor material. However, with nanoparticles being the new building blocks of the active layer, the core-shell morphology achieved with these high surface energy materials is detrimental for OPV performance since after exciton dissociation, electrons can be trapped in the core. As a consequence, power conversion efficiencies of such devices were lower than that achieved with active layers deposited from organic solvents: $2.5 \%$ and 2.15 for P3HT:ICBA NPs ${ }^{21}$ and P3HT:PC ${ }_{61} \mathrm{BM}^{22}$ respectively. Kosco et al. also reported an acceptor-rich core / donor-rich shell for nanoparticles synthesized by miniemulsion (surfactant: SDS) and using PTB7-Th as 
donor and a non-fullerene acceptor eh-IDTBR. ${ }^{23}$ They attributed this morphology to the chloroform/(SDS)water interfacial tension being higher for chloroform solution with ehIDTBR compared to chloroform solution with PTB7-Th. With a solar hydrogen fuel setup, this type of morphology led to a low $\mathrm{H}_{2}$ production, as electrons trapped in the core could not reach the nanoparticle surface.

If we transition completely from fullerene to non-fullerene acceptor materials, the synthetic versatility of this new suite of materials opens up the possibility of a larger range in surface energies for the acceptor, hence in some cases promoting the formation of a donor-rich core / acceptor-rich shell nanoparticle morphology (inverted core-shell) (Figure 4b). For example, when non-fullerene acceptor eh-IDTBR, with a surface energy of $18.3 \mathrm{~mJ} \mathrm{~m}^{-2}$, is combined with P3HT, with a surface energy of $26.9 \mathrm{~mJ} \mathrm{~m}^{-2}$, eh-IDTBR-rich shell / P3HT-rich core nanoparticles are formed. ${ }^{24}$ Similarly, when the non-fullerene acceptor N2200 (surface energy $=23.7 \mathrm{~mJ} \mathrm{~m}^{-2}$ ) is combined with TQ1 (surface energy = $\left.29 \mathrm{~mJ} \mathrm{~m}^{-2}\right)$, N2200-rich shell $/ \mathrm{TQ} 1$ rich core nanoparticles are formed. Chambon et $a l .{ }^{25}$ demonstrated that a donor-rich core / acceptor-rich shell morphology (inverted core-shell) is also achievable using the nanoprecipitation method if strategic successive solvent displacement is applied. Here P3HTrich core / $\mathrm{PC}_{61} \mathrm{BM}$-rich shell nanoparticles were formed by first precipitating $\mathrm{P} 3 \mathrm{HT}$ via the addition of DMSO to THF, and then precipitating $\mathrm{PC}_{61} \mathrm{BM}$ on the surface of the $\mathrm{P} 3 \mathrm{HT}$ nanoparticles by the addition of water to DMSO. Such type of core-shell structure might also be detrimental for OPV and solar hydrogen fuel production setups, as in this case the holes would be trapped in the core. However, the study of Barr et al. highlighted that choosing donoracceptor material combinations with matched surface energies could be an efficient strategy to target molecularly intermixed nanostructures using the miniemulsion process. This morphology has proven to improve the performance of both OPV devices and nanoparticlebased $\mathrm{H}_{2}$ production setups (vide infra).

Molecularly intermixed (Figure 4c) is another frequently reported internal morphology type for organic semiconductor nanoparticles, and it is mostly reported when the nanoprecipitation method is applied. During the nanoparticle formation, the quenching action of the non-solvent leaves little time for the donor and acceptor material to self-arrange according to their differing surface energies, hence forming a molecularly intermixed nanoparticle internal structure. In the case of P3HT:PC ${ }_{61} \mathrm{BM}$ nanoparticles, utilizing chloroform as solvent and ethanol as nonsolvent in the nanoprecipitation process led to intermixed nanoparticles and unresolvable subdomains in scanning transmission X-ray microscopy (STXM). ${ }^{26}$ This type of morphology of 
organic semiconductor nanoparticles appeared to be more suitable for OPV. Indeed, Gartner et $a l .{ }^{27}$ in 2014 and Saxena et $a l .{ }^{28}$ in 2021 prepared P3HT:ICBA composite nanoparticles by nanoprecipitation using chloroform/alcohol (ethanol or methanol) as solvent/anti-solvent systems and used them in OPV devices. The champion cells gave PCEs of $4.1 \%$ and $3.5 \%$ for chloroform/methanol and chloroform/ethanol, respectively. ${ }^{27}$ Interestingly, Saxena et al. showed that P3HT:ICBA devices prepared from colloidal dispersions gave similar performance to those prepared from halogeno-aromatic solvents, $3.5 \%$ and $3.6 \%$ respectively. ${ }^{28}$ But more importantly, the performance was improved compared to devices with the same donor:acceptor combination but prepared from the miniemulsion technique $(2.5 \%),{ }^{21}$ highlighting the beneficial effect of a molecularly intermixed morphology. In 2018, Xie et al. reported a thorough study of P3HT:ICBA nanoparticles formed by nanoprecipitation using chloroform/alcohol as the solvent/anti-solvent system and a robot-based high-throughput method $^{29}$ and managed to improve the performance of these types of devices up to $4.52 \%$. The morphology of active layers prepared from the colloidal dispersions was studied by STXM and revealed a finer phase-separation, finer than that obtained with miniemulsion. The morphology was finer than what is resolvable with STXM, a technique with a resolution limit of $30 \mathrm{~nm}$, hence the domain size was $<30 \mathrm{~nm}$. This intermixed morphology improves exciton dissociation and charge transport which is likely to explain the better performance in OPV.

Nanoparticles with non-fullerene acceptors have also been prepared by nanoprecipitation. Xie et al. compared the performance of OPV devices fabricated with four different kinds of donor:acceptor nanoparticles prepared either by miniemulsion (using SDS as surfactant, SDSNP) or by surfactant assisted nanoprecipitation (using F127 surfactant, cs-NP). ${ }^{13}$ In all four cases, the devices fabricated with nanoparticles synthesized by nanoprecipitation (cs-NP) outperformed those fabricated with nanoparticles synthesized by miniemulsion (SDS-NP). We can highlight that, with PBQ-QF:ITIC as donor:acceptor combination, the authors achieved $6.97 \%$ average PCE with cs-NP and only $3.98 \%$ average PCE for SDS-NP. ${ }^{13}$ The authors attributed the improved performance to efficient removal of the surfactant and higher crystallinity of the materials. Even though the morphology of cs-NP has not been deeply studied, it is likely to be molecularly intermixed since the morphology is generally quenched during the nanoprecipitation process and it may play a role in the performance enhancement compared to SDS-NP. The analysis of the impact of molecularly intermixed nanoparticle morphology on OPV devices shows that it improves the device efficiency by allowing both high exciton dissociation rate and conduction pathways for charge extraction. Therefore, it is 
likely that this type of molecular arrangement in the nanoparticle is also more suitable for nanoparticle-based hydrogen solar fuel production setups, as electrons and holes will have pathways to reach the surface of the nanoparticle.

A similar morphology category, described as distributed nano-domains (Figure 4d), was reported by Subianto et al. ${ }^{30}$ and Kosco et al. ${ }^{23}$ This morphology was achieved by using a surfactant which has a functional group with greater affinity for the donor material and a second functional group with greater affinity for the acceptor material. Subianto et al. utilized the thiophene-based surfactant 2-(3-thienyl)ethyloxybutylsulfonate sodium salt (TEBS) to produce nanoparticles of $\mathrm{P} 3 \mathrm{HT}: \mathrm{PC}_{61} \mathrm{BM}$ via the miniemulsion process, reporting a morphology type of distributed nano-domains from small angle neutron scattering (SANS) data. Kosco et al. reported PTB7-Th:eh-IDTBR nanoparticles exhibiting a morphology comprised of distributed nano-domains, when using TEBS as surfactant. They suggested that such morphology was obtained due to similar chloroform/water interfacial tensions whether PTB7-Th or eh-IDTBR is dissolved in the oil phase, which is not the case when SDS is used. In hydrogen solar fuel production setups, the distributed nanodomain morphology improved the $\mathrm{H}_{2}$ evolution rate from $3,044 \pm 332 \mu \mathrm{mol} \mathrm{h} \mathrm{h}^{-1}$ to $28,133 \pm 3,067 \mu \mathrm{mol} \mathrm{h}^{-1} \mathrm{~g}^{-1}$, compared to the core-shell morphology. ${ }^{23}$ This improvement was attributed to the available conduction pathways for electrons to reach the nanoparticle surface (See “... To Solar Hydrogen Fuel Production” section for details).

A fifth morphology category, biphasic/Janus (Figure 4e), while familiar to the field of nanoparticles in general, is less common to organic semiconductor nanoparticles and has only been theorized by Landfester et al. $^{31}$ using a model system of polystyrene:poly(propylene carbonate) (PS:PCC). The authors showed that biphasic nanoparticles were formed from these two immiscible polymers by the miniemulsion process. They theorized that biphasic nanoparticles could also be formed of immiscible combinations of donor and acceptor semiconductor polymers, such as PFB:F8BT. This morphology has not been tested in devices, neither OPV nor hydrogen solar fuel production setups. However, it is expected to be the ideal morphology since Janus nanoparticle of small diameters $(<40 \mathrm{~nm})$ could combine high exciton dissociation rate and perfect conduction pathways for both charges. 


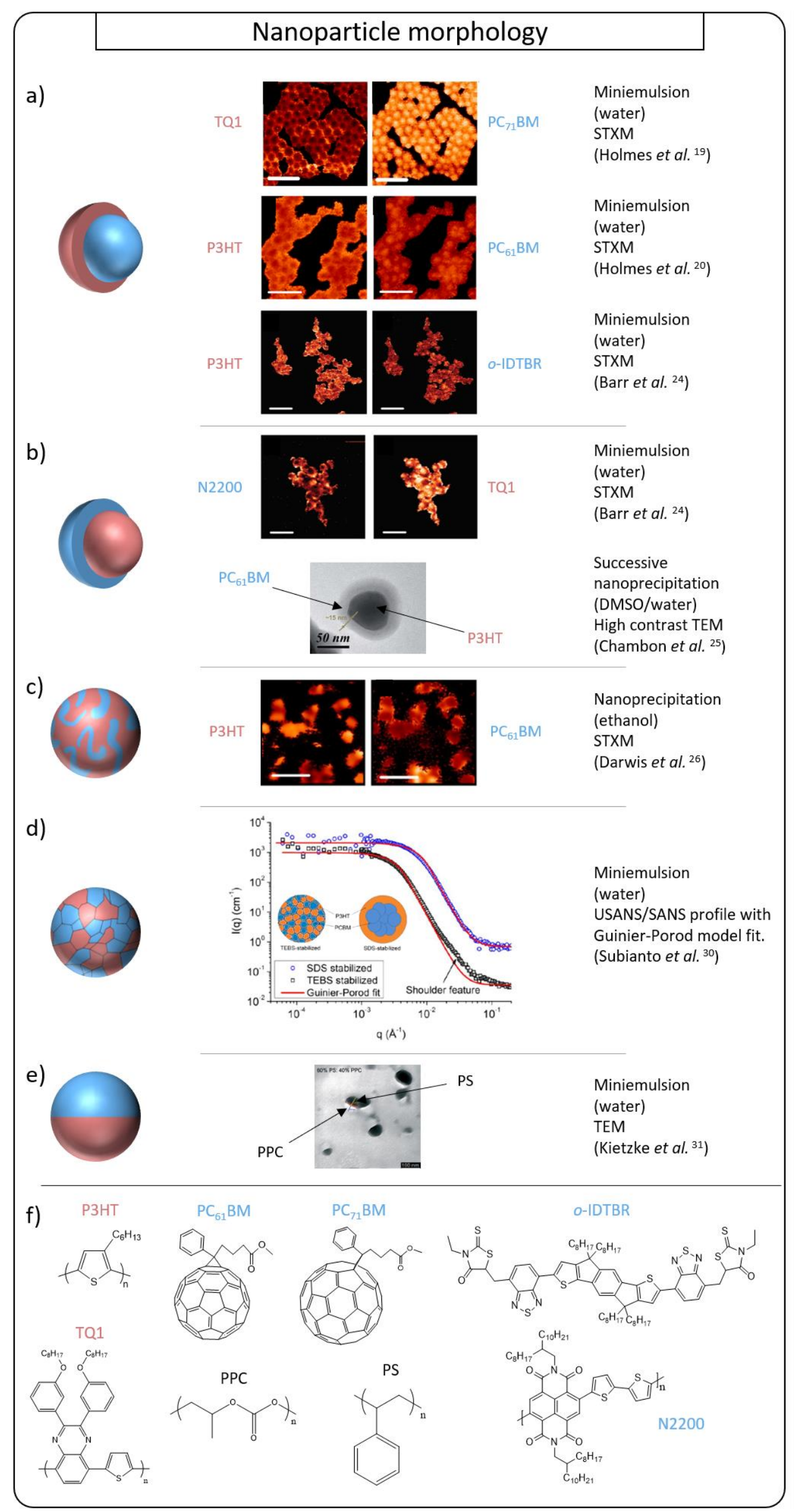


Figure 4. Nanoparticle morphology categories reported in the literature. With (a) core-shell, (b) inverted core-shell, (c) molecularly intermixed, (d) distributed nano-domains and (e) biphasic/Janus morphologies. Chemical structures of organic semiconductors (and polymers) described can be found in panel (f). Scale bars are $600 \mathrm{~nm}$ (Holmes et al. $\left.{ }^{19,20}\right), 1 \mu \mathrm{m}$ (Barr et al. ${ }^{24}$ ) and $500 \mathrm{~nm}$ (Darwis et al. ${ }^{26}$ ).

\section{...To Solar Hydrogen Fuel Production}

The many lessons taken from research in organic photovoltaics allowed the recent use of conjugated polymers as photocatalysts for hydrogen evolution to be rapidly efficient. Let us present the basics of this technology. Solar energy can be stored in the form of the chemical bond of a fuel and later be supplied on demand. $\mathrm{H}_{2}$ is the cleanest solar fuel since it only releases water as a product and electricity. $\mathrm{H}_{2}$ is produced from photocatalytic water splitting through the reaction $\mathrm{H}_{2} \mathrm{O} \rightarrow \mathrm{H}_{2}+\frac{1}{2} \mathrm{O}_{2}$ with an energy barrier of $1.23 \mathrm{eV}$. This barrier can be overcome by the energy brought by the photons, absorbed by the semiconductors. The absorption generates the exciton from which electron $\left(e^{-}\right)$and hole $\left(h^{+}\right)$take part in reduction and oxidation processes respectively (Figure 5). Therefore, the basic conditions for the use of semiconductors as light harvesting materials for hydrogen evolution are: i) a band-gap allowing the absorption of the solar irradiation (mainly from 1 to $3 \mathrm{eV} v s$ vacuum), ii) a LUMO presenting a potential lower than the one used to reduce $\mathrm{H}^{+}\left(2 H^{+}+2 e^{-} \rightarrow H_{2}\right.$, at $p H=0, \mathrm{E}=0 \mathrm{~V}$ vs NHE or 4.44 eV vs vacuum) and iii) a HOMO energy set at a higher potential than the one needed to oxidize water $\left(2 h^{+}+2 \mathrm{H}_{2} \mathrm{O} \rightarrow 4 \mathrm{H}^{+}+\frac{1}{2} \mathrm{O}_{2}\right.$, at $\mathrm{pH}=0, \mathrm{E}=1.23 \mathrm{~V} v s \mathrm{NHE}$ or $5.67 \mathrm{eV} v s$ vacuum). For $\mathrm{H}_{2}$ evolution especially, this last point can be overcome with the use of a sacrificial organic electron donor (for example trimethylamine or ascorbic acid) to fill the semiconductor HOMO and regenerate the material. In this case, an acidic medium is required to provide enough protons. We chose here to present the recent studies that are elegant strategies to understand the overall mechanism and improve the efficiency of the hydrogen photocatalysis by organic nanoparticles.

In 2016, Tian and co-workers were the first to use nanoparticles made of poly[(9,9'dioctylfluorenyl-2,7-diyl)-co-(1,4-benzo- $\left\{2,1^{\prime}, 3\right\}$ thiadiazole)] (PFBT in Figure 5) for $\mathrm{H}_{2}$ evolution. The particles (30 to $50 \mathrm{~nm}$ diameter) were prepared by nanoprecipitation, stabilized with an amphiphilic comb copolymer polystyrene-comb-poly(ethylene oxide) classically used for photovoltaics. The particles were then dispersed in water at $\mathrm{pH} 4$, with ascorbic acid as a sacrificial electron donor and the reactor was irradiated with an LED lamp $(\lambda>420 \mathrm{~nm})$. An initial rate constant for hydrogen generation of $8 \mathrm{mmolh}^{-1} \mathrm{~g}^{-1}$ was measured. They demonstrated that stabilizing the nanoparticles using this surfactant greatly improved the catalytic activity, 
by creating small nanoparticles. However, after 1 hour exposure, particle aggregation led to a loss of activity. ${ }^{32}$ Years later, in 2021, the same group increased the stability of the catalytic activity by anchoring the PFBT dots at the surface of commercially available cross-linked dextran beads. ${ }^{33}$ By precipitating the mixture of the conjugated polymer and the microbeads from THF to water, they created raspberry-like microparticles in which polymer dots and their clusters were formed upon the microbead substrates. With the assistance of this template, the immobilized PFBT increased the hydrogen evolution as compared to the unsupported polymer dots. The stability of the catalytic activity was elongated from several hours to more than $80 \mathrm{~h}$.

In 2017, Pati et al. improved the efficiency of the $\mathrm{H}_{2}$ evolution rates (HER) to $50 \mathrm{mmolh}^{-1} \mathrm{~g}^{-1}$ by reducing the polymer bandgap, a well-known strategy to harvest more photons from the sunlight, introducing thiophene spacers between the donor and acceptor units (PFODTBT in Figure 5). Most importantly, they proved, by density functional theory calculation, that the nitrogen atoms are the catalytic binding sites with protons. ${ }^{14}$

A co-catalyst, such as platinum (Pt), can also be used to increase the rate of the hydrogen production by providing active reaction sites and suppressing the charge recombination and reverse reactions. ${ }^{34}$ With the aim to bind the co-catalyst, Chou and co-workers synthesized a conjugated cycloplatinated polymer, in which the platinum complex unit is linked to the conjugated backbone (PFTFQ-PtPy in Figure 5). The authors used the same preparation process as Tian and co-workers and measured a HER of $12 \mathrm{mmolh}^{-1} \mathrm{~g}^{-1}$ that was lower than previously reported, but the stability was increased to 10 hours. $^{15}$

Alike platinum, palladium $\left(\mathrm{Pd}^{0}\right)$ is known as a highly active HER electrocatalyst. Yet, many conjugated polymers (including the one mentioned in Tian and Chou's papers) ${ }^{14,15,32}$ are synthesized by cross-coupling reaction catalyzed by $\mathrm{Pd}$, which is difficult to completely eliminate at the purification stage. Thus, Kosco et al. investigated the HER of particles made of the same polymer poly(9,9-dioctyl fluorene-alt-benzothiadiazole) containing different amounts of residual $\mathrm{Pd}$, from 1 to $1000 \mathrm{ppm} .{ }^{16}$ When all $\mathrm{Pd}$ was removed (1 ppm), no $\mathrm{H}_{2}$ evolution was observed. Then the HER increased with Pd content until it reached a plateau up to $160 \mu \mathrm{molh}^{-1} \mathrm{~g}^{-1}$ at around $200 \mathrm{ppm}$. It is thus important to always measure the residual catalyst content in these types of studies.

Chemistry will certainly be an efficient tool to improve the performance of organic nanoparticles. $\mathrm{Hu}$ et al. synthesized three polymers based on the same conjugated backbone but bearing different side chains, one alkyl hydrophobic and two hydrophilic oligo(ethylene 
oxide) (EO) presenting 4 and 7 units (see Figure 5, PBDTBT-7EO). ${ }^{35}$ The PBDTBT-7EO could improve the HER by a factor of 90 over that of alkyl-functionalized conjugated polymers. This was attributed to the positive effects of OE; (i) the creation of smaller particles (around $6 \mathrm{~nm}$ ) which increased the interfacial area of NPs/water, (ii) the creation of interactions between EO side chains and both Pt co-catalyst and protons, which improved charge transfer.

Extensively demonstrated through the photovoltaic field, organic semiconductors suffer from their high exciton binding energies, which lead to short exciton diffusion lengths. Therefore, most of the excitons generated by light absorption recombine before reaching the nanoparticle interface with water. Kosco et al. then had the idea to introduce in the particles a bulk heterojunction of two materials, the PTB7-Th polymer donor and the non-fullerene acceptor eh-IDTBR (Figure 5), to increase exciton dissociation. ${ }^{23}$ The authors prepared nanoparticles by miniemulsion using two different surfactants, SDS and sodium 2-(3thienyl)ethyloxybutylsulfonate (TEBS), which lead to different morphologies, core-shell and bulk heterojunction (distributed nano-domains), respectively. The first conclusion is that the HER of the blends were higher than the single-component nanoparticles, by at least a factor of 30 ( $\mathrm{Pt}$ is used as a co-catalyst). The second point is that the core-shell morphology, in which the core is formed by the acceptor, is 9 times less efficient (the electrons are trapped in the core) in catalyzing the $\mathrm{H}_{2}$ evolution than the bulk heterojunction (distributed nano-domains) morphology. Finally, by optimizing the Pt loading, the authors reached a HER record of 64 $\mathrm{mmolh}^{-1} \mathrm{~g}^{-1}$. 


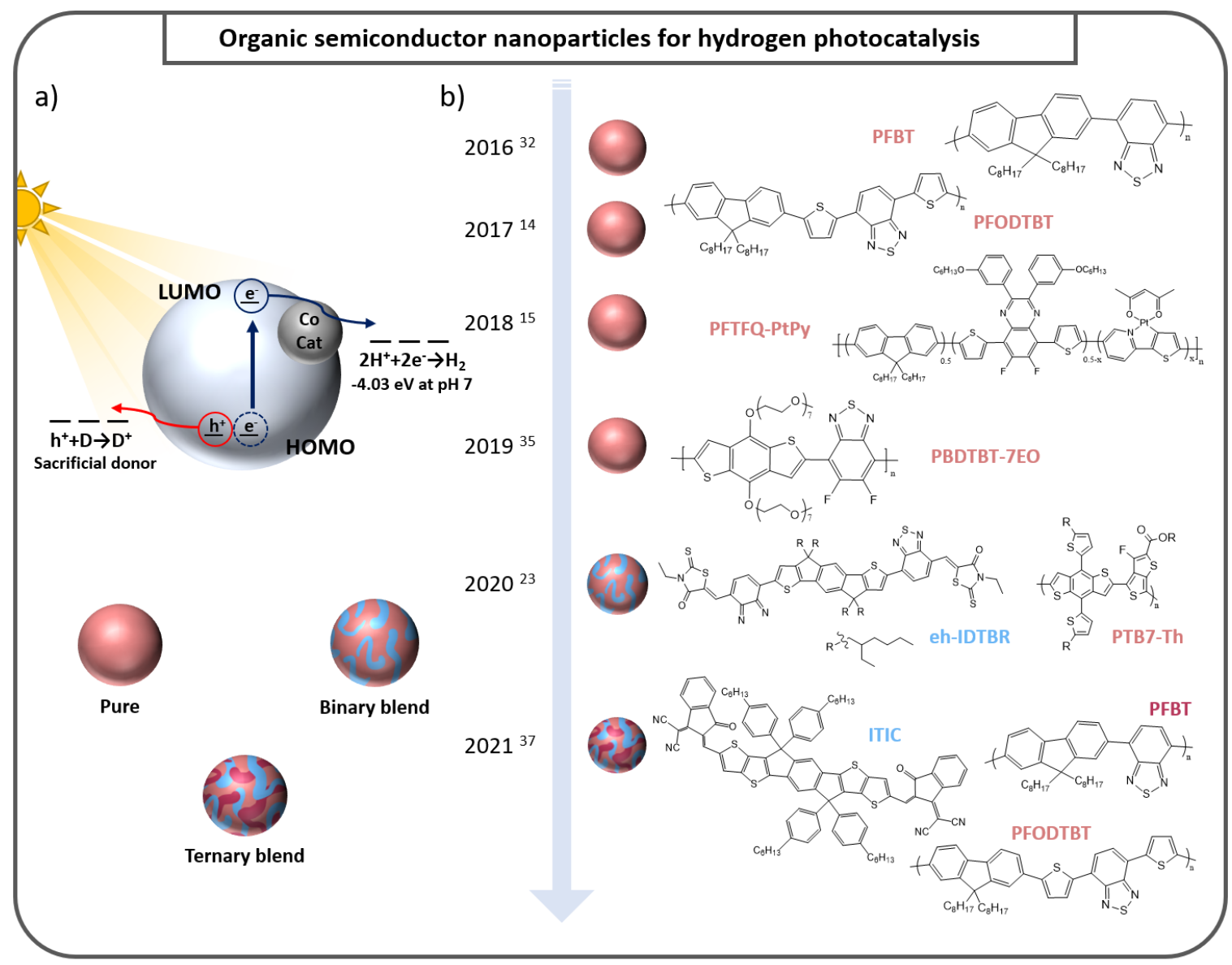

Figure 5. a) $\mathrm{H}_{2}$ photocatalysis mechanism. b) Organic semiconductors used in the selected studies.

At the same time of Kosco's report, Cooper's group published a large library of 237 binary and ternary donor/acceptor nanoparticles made by nanoprecipitation without the use of a surfactant. ${ }^{36}$ They used five different polymer electron donors and four small molecule electron acceptors, either fullerene or non-fullerene. They found that binary or ternary blends greatly outperform the pure constituent donor or acceptor particles in terms of $\mathrm{H}_{2}$ production. The blends made from the non-fullerene acceptor ITIC-2F gave highest initial photocatalytic performance, which again relates to recent progress in OPV, but experienced a very low stability due to rapid aggregation. The PCDTBT/PC ${ }_{61} \mathrm{BM}$ blend was eventually the champion, with a high hydrogen evolution rate of $105.2 \mathrm{mmol} \mathrm{h}^{-1} \mathrm{~g}^{-1}(\lambda=420 \mathrm{~nm}$, platinum, ascorbic acid $)$ and a stability of around one day. Interestingly, in some cases, the ternary blends outperformed the parent's binary blends. Although the authors could not investigate this point, it opens the door for potential future optimization.

Indeed, in 2021, Liu et al. ${ }^{37}$ reported the use of panchromatic ternary polymer dots consisting of two organic conjugated polymers (PFBT and PFODTBT) as energy and electron donors and a small molecule (ITIC) as energy and electron acceptor to complementarily harvest the 
photons from 350 to $750 \mathrm{~nm}$. They produced particles of $90 \mathrm{~nm}$ by nanoprecipitation with a polystyrene-poly(ethylene glycol) copolymer used as surfactant. They measured a maximum photocatalytic hydrogen evolution of $60.8 \pm 6.7 \mathrm{mmolh}^{-1} \mathrm{~g}^{-1}$ with the assistance of a $\mathrm{Pt}$ cocatalyst and ascorbic acid as sacrificial electron donor. Interestingly, this highest efficiency was achieved when the ITIC content was $55 \%$ of the blend corresponding to the ratio when the highest ITIC fluorescence quenching yield was observed by steady-state fluorescence measurement. The stability of the hydrogen generation was held at $50 \%$ of the initial performance after $120 \mathrm{~h}$. Given the complex nature of the system, three components, the charge and energy transfer pathways were investigated in detail by transient absorption spectroscopy measurements. They discovered that excitation energy transfer from excited PFBT to PFODTBT and ITIC within 600 fs occurred, and charge transfer between PFODTBT and ITIC happened within $200 \mathrm{fs}$.

\section{Conclusion and Perspectives}

The development of organic semiconductor colloidal dispersions has shown significant progress in the past decade for applications in both photovoltaics and photocatalytic hydrogen evolution. The key benefit of nanoparticles for photocatalytic hydrogen evolution over thin films being the increased interface area for the reaction to take place. In addition, the benefits of organic semiconductors over existing photocatalysts, such as inorganic semiconductors, include a broader absorbance, higher quantum efficiency and lower toxicity.

The extensive research on the organic photovoltaic side led to the development of different methods to overcome the issues limiting the efficiency of the devices, and in particular on the control over nanoparticle morphology. The morphology of the nanoparticle has shown to be tunable either by i) matching surface energies of the donor and acceptor materials and/or ii) playing with the interfacial energy via the use of alternative surfactants. From the experience developed in the OPV field, it appears that the molecularly intermixed morphology is more suitable for OPV devices since it can both enable high exciton dissociation rate and conduction pathways for charge extraction. Such characteristics are also likely to be a requirement for solar fuel production and the first reports showed that an intermixed morphology outperforms a coreshell morphology.

Although the field of organic semiconductor nanoparticles for solar fuel production is very young, interesting findings were achieved thanks to the knowledge gained from photovoltaics research, such as the promising use of a bulk heterojunction to increase exciton dissociation 
efficiency and thus HER. These ideas might also be applicable to carbon dioxide reduction to produce other solar fuels like ethanol. Wang et al. have fabricated a biohybrid material made of chloroplast and conjugated polymer nanoparticles to improve photosynthesis. ${ }^{38}$ The nanoparticles were added to increase the absorption of the chloroplast in the UV region. Improving photocatalytic activity will require an interdisciplinary field of action to better understand and improve the charge transfer from light absorber to co-catalyst and protons. The development of nanoparticles bearing covalently attached catalytic sites (to prevent from catalyst delamination), the use of earth-abundant elements (instead of rare-metal platinum), or the synthesis of porous or proton permeable particles, are strategies that need to be pursued in the future. Of course, the main issue towards the viability of this technology lies in the stability of the conjugated materials in the condition of potential and $\mathrm{pH}$ in a water and oxygen medium, even more if the oxidation of water is involved to cover the all-water splitting. This point will need to be extensively studied by applying standardized methodologies that are applicable in the different laboratories involved in the field.

\section{Conflicts of Interest}

There are no conflicts of interest to declare.

\section{Acknowledgements}

N.P.H. acknowledges the equipment and expertise provided by the Sydney Node of Microscopy Australia, located at the University of Sydney. This work was made possible thanks to the financial support of E2S (Energy and Environment Solutions) of the Université de Pau et Pays de l'Adour. S.C. acknowledges the support provided by the ANR through the WATER-PV project $\mathrm{N}^{\circ}$ ANR-20-CE05-0002-01 and IRP NextPV-II, through CNRS (INC and INSIS) and RCAST/University of Tokyo. The work at LIMMS/CNRS and IIS, University of Tokyo has been partly supported by KAKENHI from JSPS (20H05660).

\section{References}

Papers of particular interest, published within the period of review, have been highlighted as:

* of special interest

** of outstanding interest

(1) Pinaud, B. A.; Benck, J. D.; Seitz, L. C.; Forman, A. J.; Chen, Z.; Deutsch, T. G.; James, B. D.; Baum, K. N.; Baum, G. N.; Ardo, S.; et al. Technical and Economic Feasibility of Centralized Facilities for Solar Hydrogen Production via Photocatalysis and Photoelectrochemistry. Energy Environ. Sci. 2013, 6 (7), 1983-2002.

(2) Yanagida, S.; Kabumoto, A.; Mizumoto, K.; Pac, C.; Yoshino, K. Poly(p-Phenylene)Catalysed Photoreduction of Water. J. Chem. Soc. Chem. Commun. 1985, 474-475.

(3) Holmes, A.; Deniau, E.; Lartigau-dagron, C.; Bousquet, A.; Chambon, S.; Holmes, N. 
P. Review of Waterborne Organic Semiconductor Colloids for Photovoltaics. ACS Nano 2021, 15 (3), 3927-3959.

(4) Wu, K. J.; Tse, E. C. M.; Shang, C.; Guo, Z. Nucleation and Growth in Solution Synthesis of Nanostructures - From Fundamentals to Advanced Applications. Prog. Mater. Sci. 2021, In Press, 100821.

(5) Rymaruk, M. J.; O’Brien, C. T.; Brown, S. L.; Williams, C. N.; Armes, S. P. RAFT Dispersion Polymerization of Benzyl Methacrylate in Silicone Oil Using a SiliconeBased Methacrylic Stabilizer Provides Convenient Access to Spheres, Worms, and Vesicles. Macromolecules 2020, 53, 1785-1794.

(6) Sugimoto, T. Monodispersed Particles; Elsevier, 2019.

(7) Howe, D. H.; Hart, J. L.; McDaniel, R. M.; Taheri, M. L.; Magenau, A. J. D. Functionalization-Induced Self-Assembly of Block Copolymers for Nanoparticle Synthesis. ACS Macro Lett. 2018, 7 (12), 1503-1508.

(8) Ito, T.; Shirakawa, H.; Ikeda, S. Simultaneous Polymerization and Formation of Polyacetylene Film on the Surface of Concentrated Soluble Ziegler-Type Catalyst Solution. J. Polym. Sci. Polym. Chem. Ed. 1974, 12, 11-20.

(9) Salzner, U.; Lagowski, J. B.; Pickup, P. G.; Poirier, R. A. Comparison of Geometries and Electronic Structures of Polyacetylene, Polyborole, Polycyclopentadiene, Polypyrrole, Polyfuran, Polysilole, Polyphosphole, Polythiophene, Polyselenophene and Polytellurophene. Synth. Met. 1998, 96 (3), 177-189.

(10) Landfester, K.; Montenegro, R.; Scherf, U.; Güntner, R.; Asawapirom, U.; Patil, S.; Neher, D.; Kietzke, T. Semiconducting Polymer Nanospheres in Aqueous Dispersion Prepared by a Miniemulsion Process. Adv. Mater. 2002, 14 (9), 651-655.

(11) Xie, C.; Classen, A.; Späth, A.; Tang, X.; Min, J.; Meyer, M.; Zhang, C.; Li, N.; Osvet, A.; Fink, R. H.; et al. Overcoming Microstructural Limitations in Water Processed Organic Solar Cells by Engineering Customized Nanoparticulate Inks. Adv. Energy Mater. 2018, 8, 1702857.

(12) Palacio Valera, A.; Schatz, C.; Ibarboure, E.; Kubo, T.; Segawa, H.; Chambon, S. Elaboration of PCBM Coated P3HT Nanoparticles: Understanding the Shell Formation. Front. Energy Res. 2019, 6, 146.

(13) *Xie, C.; Heumüller, T.; Gruber, W.; Tang, X.; Classen, A.; Schuldes, I.; Bidwell, M.; Späth, A.; Fink, R. H.; Unruh, T.; et al. Overcoming Efficiency and Stability Limits in Water-Processing Nanoparticular Organic Photovoltaics by Minimizing Microstructure Defects. Nat. Commun. 2018, 9, 5335.

The authors achieve the highest reported NP-OPV efficiency to date of $7.5 \%$ by using a CMC switching strategy with poloxamer Pluronic F127 as surfactant, and donor-acceptor system PBQ-QF:ITIC.

(14) Pati, P. B.; Damas, G.; Tian, L.; Fernandes, D. L. A.; Zhang, L.; Pehlivan, I. B.; Edvinsson, T.; Araujo, C. M.; Tian, H. An Experimental and Theoretical Study of an Efficient Polymer Nano-Photocatalyst for Hydrogen Evolution. Energy Environ. Sci. 2017, 10 (6), 1372-1376.

(15) Tseng, P. J.; Chang, C. L.; Chan, Y. H.; Ting, L. Y.; Chen, P. Y.; Liao, C. H.; Tsai, M. L.; Chou, H. H. Design and Synthesis of Cycloplatinated Polymer Dots as 
Photocatalysts for Visible-Light-Driven Hydrogen Evolution. ACS Catal. 2018, 8 (9), 7766-7772.

(16) Kosco, J.; McCulloch, I. Residual Pd Enables Photocatalytic H2 Evolution from Conjugated Polymers. ACS Energy Lett. 2018, 3 (11), 2846-2850.

(17) Kietzke, T.; Neher, D.; Landfester, K.; Montenegro, R.; Güntner, R.; Scherf, U. Novel Approaches to Polymer Blends Based on Polymer Nanoparticles. Nat. Mater. 2003, 2 (6), 408-412.

(18) Pan, X.; Sharma, A.; Gedefaw, D.; Kroon, R.; Diaz de Zerio, A.; Holmes, N. P.; Kilcoyne, A. L. D.; Barr, M. G.; Fahy, A.; Marks, M.; et al. Environmentally Friendly Preparation of Nanoparticles for Organic Photovoltaics. Org. Electron. 2018, 59, 432 440.

(19) Holmes, N. P.; Marks, M.; Kumar, P.; Kroon, R.; Barr, M. G.; Nicolaidis, N.; Feron, K.; Pivrikas, A.; Fahy, A.; Diaz De Zerio Mendaza, A.; et al. Nano-Pathways: Bridging the Divide Between Water-Processable Nanoparticulate and Bulk Heterojunction Organic Photovoltaics. Nano Energy 2016, 19, 495-510.

(20) Holmes, N. P.; Nicolaidis, N.; Feron, K.; Barr, M.; Burke, K. B.; Al-Mudhaffer, M.; Sista, P.; Kilcoyne, A. L. D.; Stefan, M. C.; Zhou, X.; et al. Probing the Origin of Photocurrent in Nanoparticulate Organic Photovoltaics. Sol. Energy Mater. Sol. Cells 2015, 140, 412-421.

(21) Ulum, S.; Holmes, N.; Barr, M.; Kilcoyne, A. L. D.; Gong, B. Bin; Zhou, X.; Belcher, W.; Dastoor, P. The Role of Miscibility in Polymer:Fullerene Nanoparticulate Organic Photovoltaic Devices. Nano Energy 2013, 2, 897-905.

(22) Gehan, T. S.; Bag, M.; Renna, L. A.; Shen, X.; Algaier, D. D.; Lahti, P. M.; Russell, T. P.; Venkataraman, D. Multiscale Active Layer Morphologies for Organic Photovoltaics through Self-Assembly of Nanospheres. Nano Lett. 2014, 14, 5238 5243.

(23) **Kosco, J.; Bidwell, M.; Cha, H.; Martin, T.; Howells, C. T.; Sachs, M.; Anjum, D. H.; Gonzalez Lopez, S.; Zou, L.; Wadsworth, A.; et al. Enhanced Photocatalytic Hydrogen Evolution from Organic Semiconductor Heterojunction Nanoparticles. Nat. Mater. 2020, 19 (5), 559-565.

Organic semiconductor nanoparticles of PTB7-Th:eh-IDTBR were applied to hydrogen evolution photocatalysis, with the outcome being a greatly enhanced photocatalytic activity of $64 \mathrm{mmol} \mathrm{h}^{-1} \mathrm{~g}^{-1}$. The internal donor-acceptor heterojunction greatly improved charge generation and hence photocatalytic activity in comparison with nanoparticles formed from a single semiconductor.

(24) *Barr, M. G.; Chambon, S.; Fahy, A.; Jones, T. W.; Marcus, M. A.; Kilcoyne, A. L. D.; Dastoor, P. C.; Griffith, M. J.; Holmes, N. P. Nanomorphology of Eco-Friendly Colloidal Inks, Relating Non-Fullerene Acceptor Surface Energy to Structure Formation. Mater. Chem. Front. 2021, 5 (5), 2218-2233.

The authors are the first to report a core-shell flipping effect for polymer:NFA nanoparticles using the miniemulsion technique, when the surface energy of NFAs is lower than that of polymer donors. The results reveal a nano-engineering strategy for the future, targeting 
molecularly intermixed nanostructures by synthetically modifying the side chain chemistry of NFAs in order to achieve matched surface energy donor-acceptor pairs.

(25) Chambon, S.; Schatz, C.; Sébire, V.; Pavageau, B.; Wantz, G.; Hirsch, L. Organic Semiconductor Core-Shell Nanoparticles Designed through Successive Solvent Displacements. Mater. Horizons 2014, 1 (4), 431-438.

(26) Darwis, D.; Holmes, N.; Elkington, D.; David Kilcoyne, A. L.; Bryant, G.; Zhou, X.; Dastoor, P.; Belcher, W. Surfactant-Free Nanoparticulate Organic Photovoltaics. Sol. Energy Mater. Sol. Cells 2014, 121, 99-107.

(27) Gärtner, S.; Christmann, M.; Sankaran, S.; Röhm, H.; Prinz, E.-M.; Penth, F.; Pütz, A.; Türeli, A. E.; Penth, B.; Baumstümmler, B.; et al. Eco-Friendly Fabrication of 4\% Efficient Organic Solar Cells from Surfactant-Free P3HT:ICBA Nanoparticle Dispersions. Adv. Mater. 2014, 26, 6653-6657.

(28) Saxena, S.; Marlow, P.; Subbiah, J.; Colsmann, A.; Wong, W. W. H.; Jones, D. J. Pyridine End-Capped Polymer to Stabilize Organic Nanoparticle Dispersions for Solar Cell Fabrication through Reversible Pyridinium Salt Formation. ACS Appl. Mater. Interfaces 2021, 13 (30), 36044-36052.

(29) Xie, C.; Tang, X.; Berlinghof, M.; Langner, S.; Chen, S.; Späth, A.; Li, N.; Fink, R. H.; Unruh, T.; Brabec, C. J. Robot-Based High-Throughput Engineering of Alcoholic Polymer: Fullerene Nanoparticle Inks for an Eco-Friendly Processing of Organic Solar Cells. ACS Appl. Mater. Interfaces 2018, 10 (27), 23225-23234.

(30) Subianto, S.; Balu, R.; Campo, L. De; Sokolova, A.; Dutta, N. K.; Choudhury, N. R.; Balu, R.; Campo, L. De; Sokolova, A.; Dutta, N. K.; et al. Sulfonated Thiophene Derivative Stabilized Aqueous Poly(3-Hexylthiophene):Phenyl-C61-Butyric Acid Methyl Ester Nanoparticle Dispersion for Organic Solar Cell Applications. ACS Appl. Mater. Interfaces 2018, 10, 44116-44125.

(31) Kietzke, T.; Neher, D.; Kumke, M.; Ghazy, O.; Ziener, U.; Landfester, K. Phase Separation of Binary Blends in Polymer Nanoparticles. Small 2007, 3 (6), 1041-1048.

(32) Wang, L.; Fernández-Terán, R.; Zhang, L.; Fernandes, D. L. A.; Tian, L.; Chen, H.; Tian, H. Organic Polymer Dots as Photocatalysts for Visible Light-Driven Hydrogen Generation. Angew. Chemie - Int. Ed. 2016, 55 (40), 12306-12310.

(33) Liu, A.; Tian, L.; Tian, H. In Situ Preparation and Immobilization of Semiconducting Polymer Dots on Microbeads for Efficient and Stable Photocatalytic Hydrogen Evolution. ACS Appl. Energy Mater. 2021, 4 (5), 4308-4312.

(34) Yang, J.; Wang, D.; Han, H.; Li, C. Roles of Cocatalysts in Photocatalysis and Photoelectrocatalysis. Acc. Chem. Res. 2013, 46 (8), 1900-1909.

(35) Hu, Z.; Wang, Z.; Zhang, X.; Tang, H.; Liu, X.; Huang, F.; Cao, Y. Conjugated Polymers with Oligoethylene Glycol Side Chains for Improved Photocatalytic Hydrogen Evolution. iScience 2019, 13, 33-42.

(36) **Yang, H.; Li, X.; Sprick, R. S.; Cooper, A. I. Conjugated Polymer Donor-Molecular Acceptor Nanohybrids for Photocatalytic Hydrogen Evolution. Chem. Commun. 2020, 56 (50), 6790-6793. 
A large library of 237 binary and ternary blends of organic semiconductors were screened for photocatalytic $\mathrm{H}_{2}$ activity, in nanoparticulate form utilizing nanoprecipitation synthesis.

PCDTBT/PC ${ }_{61} \mathrm{BM}$ nanoparticles showed the highest $\mathrm{H}_{2}$ evolution rate of $105.2 \mathrm{mmol} \mathrm{h}^{-1} \mathrm{~g}^{-1}$.

(37) **Liu, A.; Gedda, L.; Axelsson, M.; Pavliuk, M.; Edwards, K.; Hammarström, L.; Tian, H. Panchromatic Ternary Polymer Dots Involving Sub-Picosecond Energy and Charge Transfer for Efficient and Stable Photocatalytic Hydrogen Evolution. J. Am. Chem. Soc. 2021, 143 (7), 2875-2885.

Reports the use of panchromatic ternary nanoparticles consisting of two polymers, PFBT and PFODTBT, as energy and electron donors, and one small molecule, ITIC, as energy and electron acceptor, effectively harvesting photons from 350 to $750 \mathrm{~nm}$. A maximum photocatalytic hydrogen evolution of $60.8 \pm 6.7 \mathrm{mmol} \mathrm{h}^{-1} \mathrm{~g}^{-1}$ was achieved.

(38) Wang, Y.; Li, S.; Liu, L.; Lv, F.; Wang, S. Conjugated Polymer Nanoparticles to Augment Photosynthesis of Chloroplasts. Angew. Chemie 2017, 129 (19), 5392-5395. 